\title{
Simple Quadrature Sinusoidal Oscillator with Grounded Elements
}

\author{
P. Pinkaew, P. Suwanjan, and W. Jaikla
}

\begin{abstract}
This paper presents the current-mode quadrature sinusoidal oscillator employing current controlled current differencing transconductance amplifier (CCCDTA) as active element. The proposed oscillator can provide 2 sinusoidal waveforms with high output impedance which makes the proposed oscillator can directly drive load or cascade in current mode circuit without any current buffers. The condition of oscillation (CO) and frequency of oscillation (FO) can be orthogonally controlled by mean of electronic tuning. The circuit consists of only single CCCDTA and three grounded passive elements which are ideal for implementation on an integrated circuit (IC) chip. The predicted results confirmed with Pspice simulation using BJT technology are agreed with theoretical analysis.
\end{abstract}

Index Terms-Quadrature oscillator, Integrated circuit, CCCDTA, Current-mode.

\section{INTRODUCTION}

The oscillators which generate sinusoidal wave form are extremely useful for several systems for example in telecommunication, instrument and measurement system, power electronics etc. Especially, the oscillators that provide 2 sinusoidal signals with 90 degree phase difference are frequently used in telecommunication system for quadrature mixer, single sideband generator etc. [1].

Recently, the design of analog signal processing circuits in current-mode has been receiving considerable attention due to their potential advantages for inherently wide bandwidth, higher slew-rate, greater linearity, wider dynamic range, simple circuit and low power consumption [2]-[5]. The attention has turned to use the active building block (ABB) such as the operational amplifier (Opamp), the operational transconductance amplifier (OTA), current feedback opamp (CFOA), the first generation of current conveyor (CCI), the second generation of current conveyor (CCII), the current differencing buffer amplifier (CDBA) and many other active blocks [6]-[8]. The current differencing transconductance amplifier (CDTA) [9] is the interesting current-mode active $\mathrm{ABB}$ since it is a versatile component in the realization of a class of analog signal processing circuits, especially analogue frequency filters [10]-[11]. It is really current-mode element whose input and output signals are currents. In addition, output current of CDTA can be electronically adjusted. Besides, the modified version of CDTA which the parasitic resistances at two current input ports can be electronically controlled has been proposed in [12]. This CDTA is called

Manuscript received November 27, 2012; revised March 9, 2013.

The authors are with the Department of Electrical Communication Engineering, Faculty of Industrial Education, King Mongkut's Institute of Technology Ladkrabang, Bangkok, 10520, Thailand (e-mail: phakaphon@hotmail.com, kspeeraw@gmail.com,winai.ja@hotmail.com ). current controlled current differencing transconductance amplifier (CCCDTA).

From literature survey, it is found that several implementations of oscillator employing CDTAs or CCCDTAs have been reported [13]-[24]. Unfortunately, these reported circuits suffer from one or more of following weaknesses:

- Use more than two CDTAs or CCCDTAs and excessive use of the passive elements which is not convenient to further fabricate in IC.

- Some reported circuits use multiple-output CDTA or CCCDTA. Consequently, the circuits become more complicated.

- Use floating capacitors.

- Cannot provide quadrature signal with high output impedance

The aim of this paper is to introduce a current-mode quadrature sinusoidal oscillator based on single CCCDTA. The features of the proposed circuit are the following:

- Use only single active element.

- Electronic adjustment of the CO and FO.

- High-impedance of current outputs.

- Use grounded elements which easy to implement an integrated circuit.

- Orthogonal control of CO and FO.

\section{PRinciple OF OPERATIONS}

\section{A. Basic Concept of Main Active Element}

The CCCDTA is modified from the well-known CDTA introduced by Biolek [9]. The schematic symbol and the ideal behavioral model of the CCCDTA are shown in Fig. 1(a) and (b). The characteristics of the ideal CCCDTA are represented by the following hybrid matrix:

$$
\left[\begin{array}{l}
V_{p} \\
V_{n} \\
I_{z} \\
I_{x}
\end{array}\right]=\left[\begin{array}{cccc}
R_{p} & 0 & 0 & 0 \\
0 & R_{n} & 0 & 0 \\
1 & -1 & 0 & 0 \\
0 & 0 & 0 & \pm g_{m}
\end{array}\right]\left[\begin{array}{l}
I_{p} \\
I_{n} \\
V_{x} \\
V_{z}
\end{array}\right]
$$

For the CCCDTA implemented by a BJT technology, the parasitic resistances $\left(R_{p}\right.$ and $\left.R_{n}\right)$ and transconductance $\left(g_{m}\right)$ can be expressed as

$$
R_{p}=R_{n}=\frac{V_{T}}{2 I_{B 1}}
$$




$$
g_{m}=\frac{I_{B 2}}{2 V_{T}}
$$

$V_{T}$ is the thermal voltage. $I_{B 1}$ and $I_{B 2}$ are the bias current used to control the parasitic resistances and transconductance, respectively. The symbol and the equivalent circuit of the CCCDTA are illustrated in Fig. 1 and Fig. 2, respectively. In general, CCCDTA can contain an arbitrary number of $\mathrm{z}$ terminals, called $\mathrm{z}_{\mathrm{c}}$ ( $\mathrm{z}$-copy) terminal [25]. The internal current mirror provides a copy of the current flowing out of the $\mathrm{z}$ terminal to the $\mathrm{z}_{\mathrm{c}}$ terminal.

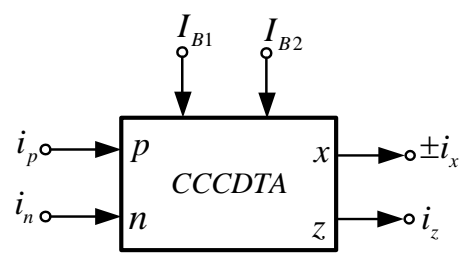

Fig. 1. Symbolic notation of CCCDTA



Fig. 2. Equivalent circuit of CCCDTA

\section{B. Proposed Current-Mode Quadrature Oscillator}

The proposed current-mode oscillator is shown in Fig. 3. It consists of single CCCDTA, single resistor and two grounded capacitors. The output currents $I_{\text {out } 1}$ and $I_{\text {out } 2}$ are high output impedance which can be directly drive load without additional current buffer and $90^{\circ}$ phase difference. Considering the proposed oscillator and using the CCCDTA properties as described in above section, the characteristic equation is obtained as

$$
s^{2}+s\left(\frac{1-R g_{m}}{C_{2} R}\right)+\frac{g_{m}}{C_{1} C_{2} R_{p}}=0 a
$$

From (4), the condition of oscillation and frequency of oscillation can be written as

$$
1=R g_{m}
$$

$$
\omega_{o s c}=\sqrt{\frac{g_{m}}{C_{1} C_{2} R_{p}}}
$$

If $R_{p}$ and $g_{m}$ are equal to (2) and (3), respectively, the CO and FO are re-written as

$$
\begin{gathered}
1=R \frac{I_{B 2}}{2 V_{T}} \\
\omega_{o s c}=\frac{1}{V_{T}} \sqrt{\frac{I_{B 1} I_{B 2}}{C_{1} C_{2}}}
\end{gathered}
$$

It can be evidently seen from (7) and (8) that the $\mathrm{CO}$ is controlled by $\mathrm{R}$ without disturbing FO. Also, the FO can be electronically tuned by $\mathrm{I}_{\mathrm{B} 1}$ without affecting $\mathrm{CO}$. From Fig. 3, the current transfer function of $I_{\text {out } 1}$ and $I_{\text {out } 2}$ is written as

$$
\frac{I_{\text {out } 2}}{I_{\text {out } 1}}=s C_{1} R_{p}
$$

It is evident from (9) that current output $I_{\text {out }}$ is phase-shifted by $90^{\circ}$ from current output $I_{\text {out } 2}$ and thus the oscillator can be used as quadrature oscillator.

The sensitivities of oscillation frequency are given as

$$
S_{C_{1}, C_{2}, R_{P}}^{\omega_{0}}=-\frac{1}{2} ; S_{g_{m}}^{\omega_{0}}=\frac{1}{2}
$$

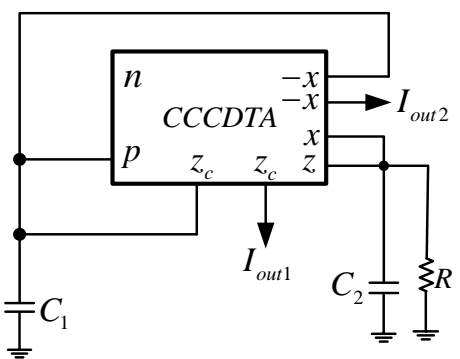

Fig. 3. Proposed simple current-mode oscillator

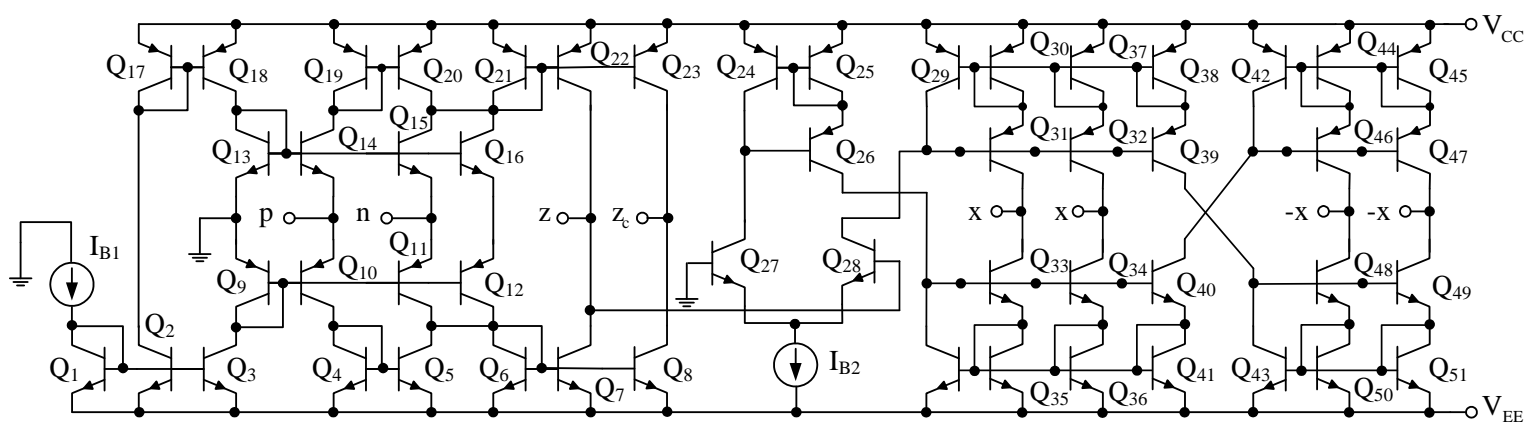

Fig. 4. Internal construction of CCCDTA 


\section{Simulation Results}

To investigate the theoretical analysis, the proposed oscillator in Fig. 2 is simulated by using the PSPICE simulation program. Internal construction of CCCDTA used in simulation is shown in Fig. 4. The PNP and NPN transistors employed in the proposed topology were simulated by respectively using the parameters of the PR200N and NR200N bipolar transistors of ALA400 transistor array from AT\&T [26]. The circuit was biased with $\pm 2.5 \mathrm{~V}$ supply voltages, $\mathrm{C}_{1}=\mathrm{C}_{2}=0.2 \mathrm{nF}, \mathrm{R}=0.4 \mathrm{k}, \mathrm{I}_{\mathrm{B} 1}=50 \mu \mathrm{A}$ and $\mathrm{I}_{\mathrm{B} 2}=122 \mu \mathrm{A}$. This yields simulated oscillation frequency of $1.891 \mathrm{MHz}$. The calculated value of FO in (8) is $2.39 \mathrm{MHz}$. Fig. 5 shows simulated quadrature output waveforms. It is seen that $I_{\text {out } 1}$ and $I_{\text {out } 2}$ are $90^{\circ}$ phase difference as explain in (9). Fig. 6 shows the simulated output spectrum, where the total harmonic distortion (THD) for $I_{\text {out } 1}$ and $I_{\text {out } 2}$ are about $0.1170 \%$ and $0.1321 \%$, respectively. The plot of simulated and calculated $\mathrm{FO}$ is compared in Fig. 7 where $\mathrm{I}_{\mathrm{B} 1}$ was varied from $10 \mu \mathrm{A}-200 \mu \mathrm{A}$ and $\mathrm{C}\left(\mathrm{C}_{1}=\mathrm{C}_{2}=\mathrm{C}\right)$ was changed to three values. It is found that the $\mathrm{FO}$ can be tuned by $\mathrm{I}_{\mathrm{B} 1}$ as shown in (8). The power dissipation is approximately $4.66 \mathrm{~mW}$.

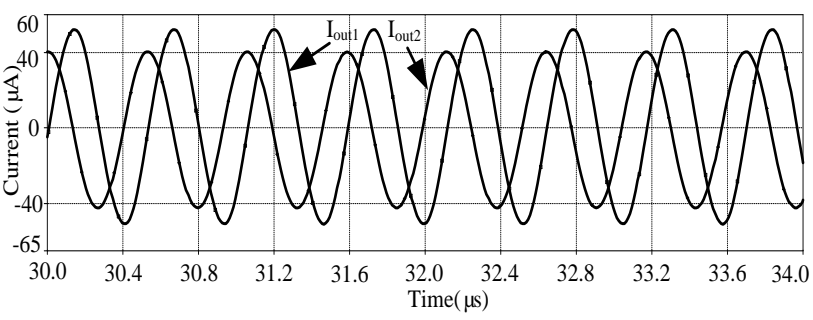

Fig. 5. Output voltage waveforms

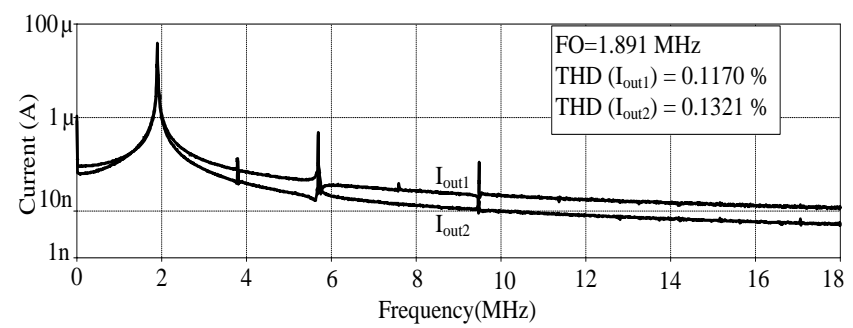

Fig. 6. Output Spectrum

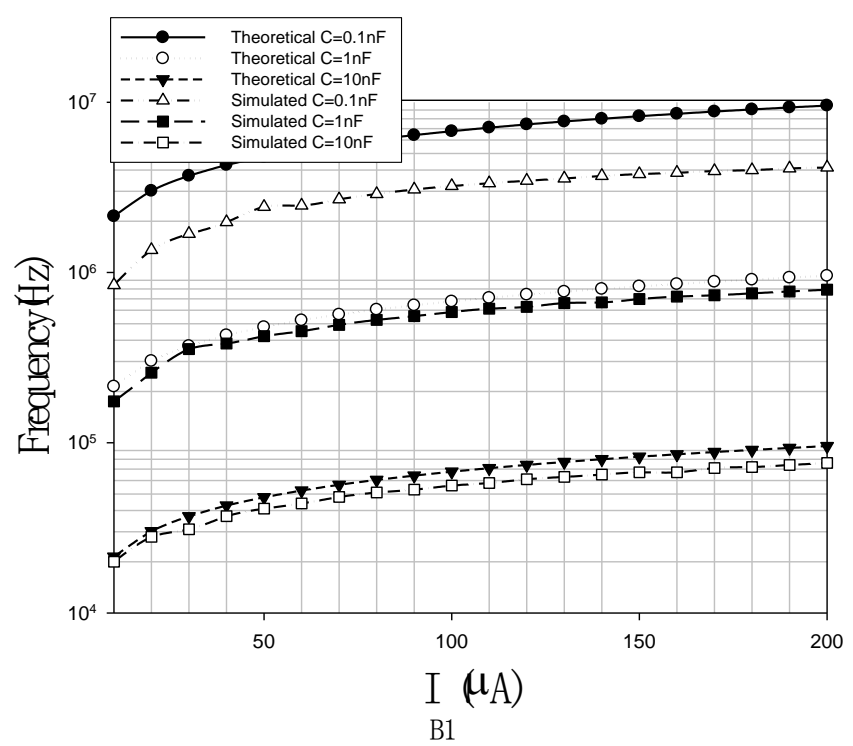

Fig. 7. Simulated FO versus calculated FO

\section{CONCLUSION}

A simple current-mode quadrature oscillator based on CCCDTA has been presented. The frequency of oscillation and condition of oscillation can be orthogonally adjusted. It consists of 1 CCCDTA, 1 resistor and 2 grounded capacitors, which is convenient to fabricate. The performances of the proposed oscillator were verified by PSpice simulation. The simulated results agree well with the theoretical anticipation.

\section{REFERENCES}

[1] I. A. Khan and S. Khawaja, "An integrable gm-C quadrature oscillator," Int. J. Electronics, vol. 87, vol. 1, pp. 1353-1357, 2000.

[2] C. Toumazou and F. J Lidgey, "Universal active filter using current conveyors," Electron. Lett., vol. 22, pp. 662-664, 1986.

[3] M. T. Abuelma'atti and H. A. Al-Zaher, "Current-mode sinusoidal oscillators using single FTFN," IEEE Trans. Circuits and Systems-II: Analog and Digital Signal Proc., pp. 69-74, vol. 46, 1999.

[4] U. Cam, A. Toker, O. Cicekoglu, and H. Kuntman, "Current-mode high output-impedance sinusoidal oscillator configuration employing single FTFN," Analog Integrated Circuits and Signal Proc., pp. 231-238, vol. 24, 2000.

[5] S. S. Gupta and R. Senani, "Realisation of current-mode SRCOs using all grounded passive elements," Frequenz, vol. 57, pp. 26-37, 2003.

[6] S. Ozcan, A. Toker, C. Acar, H. Kuntman, and O. Cicekoglu, "Single resistance-controlled sinusoidal oscillators employing current differencing buffered amplifier," Microelectronics Journal, vol. 31 no. 3, pp. 169-174, 2000.

[7] A. M. Soliman and A. S Elwakil, "Wien oscillators using current conveyors," Computers \& Electrical Engineering, vol. 25, no. 1, pp. 45-55, 1999.

[8] J. W. Horng, "Current conveyors based allpass filters and quadrature oscillators employing grounded capacitors and resistors," Computers and Electrical Engineering, vol. 31, no. 1, pp. 81-92, 2005.

[9] D. Biolek, "CDTA - Building Block for Current-Mode Analog Signal Processing," in Proceedings of the European conference on circuit theory and design, pp. 397-400, 2003.

[10] D. Biolek, V. Biolkova, and Z. Kolka, "Current-mode biquad employing single CDTA," Indian Journal of Pure \& Applied Physics, vol. 47, pp. 535-537, 2009.

[11] N. A. Shah, S. Z. Iqbal, and M. Quadri, "Current-mode Band-pass Filter Using A Single CDTA," J. of Active and Passive Electronic Devices, vol. 4, pp. 1-5, 2009.

[12] M. Siripruchyanun and W. Jaikla, "Realization of current controlled current differencing transconductance amplifier (CCCDTA) and its applications," ECTI Transactions on Electrical Engineering, Electronics, and Communications, vol. 5, no. 1, pp. 41-50, 2007.

[13] J. W. Horng, "Current-Mode third-order quadrature oscillator using CDTAs," Active and Passive Electronic Components, vol. 2009, pp. $1-5,2009$.

[14] J. W. Horng, H. Lee, and J. Y. Wu, "Electronically tunable third-order quadrature oscillator using CDTAs," Radioengineering, vol. 19, no. 2, pp. 326-330, 2010.

[15] A. U. Keskin and D. Biolek, "Current mode quadrature oscillator using current differencing transconductance amplifiers (CDTA)," IEE Proc.-Circuits Devices Syst., vol. 153, no. 3, 2006.

[16] A. Lahiri, "New current-mode quadrature oscillator using CDTA," IEICE Electronics Express, vol. 6, no. 3, pp. 135-140, 2009.

[17] A. Uygur and H. Kuntman "CDTA-Based quadrature oscillator design," in Proc. 14th European Signal processing conference (EUSIPCO 2006), September 4-8, 2006.

[18] D. Biolek, V. Biolkova, and A. Keskin, "Current mode quadrature oscillator using two CDTAs and two grounded capacitors," in Proceedings of the 5th WSEAS International Conference on System Science and Simulation in Engineering, pp. 368-370, 2006.

[19] W. Tangsrirat, T. Pukkalanun, and W. Surakampontorn, "Resistorless realization of current-mode first-order allpass filters using current differencing transconductance amplifiers," Microelectronics Journal, vol. 41, pp. 178-183, 2010.

[20] W. Jaikla, M. Siripruchyanun, J. Bajer, and D. Biolek, "A simple current-mode quadrature oscillator using single CDTA," Radioengineering, vol. 17, no. 4, pp. 33-40, 2008.

[21] Y. Li, "A new single MCCCDTA based Wien-bridge oscillator with AGC," AEU-International Journal of Electronics and Communication, vol. 66, no. 2, pp. 153-156, 2012.

[22] W. Jaikla, "A. Lahiri. Resistor-less current-mode four-phase quadrature oscillator using CCCDTAs and grounded capacitors," 
AEU-International Journal of Electronics and Communication, vol. 66, no. 3, pp. 214-218, 2012.

[23] D. Prasad, D. R. Bhaskar, and A. K. Singh, "Electronically controllable grounded capacitor current-mode quadrature oscillator using single MO-CCCDTA," Radioengineering, vol. 20, no. 1, pp. 354-359, 2011.

[24] D. Biolek, A. U. Keskin, and V. Biolkova, "Grounded capacitor current mode SRCO using single modified CDTA," IET Circuits, Devices \& Systems, vol. 4, no. 6, pp. 496-502, 2010.

[25] D. Biolek, R. Senani, V. Biolkova, and Z. Kolka, "Active elements for analog signal processing: classification, review, and new proposals," Radioengineering, vol. 17, no. 4, pp. 15-32, 2008 .

[26] D. R. Frey, "Log-domain filtering: an approach to current-mode filtering," IEE Processing Circuit Devices System, vol. 140, no. 6, pp. 406-416, 1993.

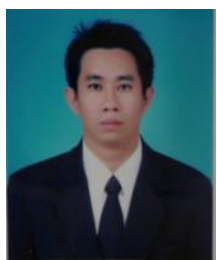

Phakaphon Pinkaew was born in Prajinburi Thailand. He received the bachelor degree in Engineering Department of Computers from Mahanakorn University of Technology, Bangkok, Thailand. Now, he is working for Master of Science in Industrial Education (M.Sc.I.Ed.) in Electrical Communication Engineering at KMITL. He has been Department of Electronics in Chonburi Technical College, Thailand, since 2002. His research interests include electronic communications, analog signal processing and analog integrated circuit



Peerawut Suwanjan received the B. S. I. Ed. degree in telecommunication engineering and $\mathrm{M}$ Eng in electrical engineering from King Mongkut's Institute of Technology Ladkrabang (KMITL), Thailand in 1992 and 1998, respectively. He has been with Department of Engineering Education, Faculty of Industrial Education, King Mongkut's Institute of Technology Ladkrabang, Bangkok, Thailand since 1992. His research interests include electronic communications, analog signal processing and analog integrated circuit.

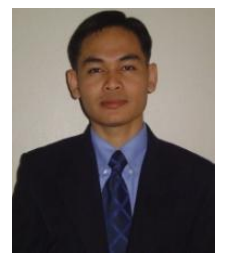

Winai Jaikla was born in Buriram, Thailand. $\mathrm{He}$ received the B. S. I. Ed. degree in telecommunication engineering from King Mongkut's Institute of Technology Ladkrabang (KMITL), Thailand in 2002, M. Tech. Ed. in electrical technology and Ph.D. in electrical education from King Mongkut's University of Technology North Bangkok (KMUTNB) in 2004 and 2010, respectively. From 2004 to 2011 he was with Electric and Electronic Program, Faculty of Industrial Technology, Suan Sunandha Rajabhat University, Bangkok, Thailand. He has been with Department of Engineering Education, Faculty of Industrial Education, King Mongkut's Institute of Technology Ladkrabang, Bangkok, Thailand since 2012. His research interests include electronic communications, analog signal processing and analog integrated circuit. He is a member of ECTI, Thailand 